\title{
Measurement of Thermal Conductivity of Sludge and Liquid Materials
}

\author{
Mária Čarnogurská ${ }^{1, *}$, Miroslav Př́íhoda $^{2}$, Tomáš Brestovič ${ }^{1}$, Marián Lázár ${ }^{1}$, Natália \\ Jasminská ${ }^{1}$, and Jiří Marek², Dušan Puškár ${ }^{1}$ \\ ${ }^{1}$ Technical University of Košice, Department of Power Engineering, Vysokoškolská 4, 04200 \\ Košice, Slovakia \\ ${ }^{2}$ VŠB - Technical University of Ostrava, Department of Thermal Engineering, 17. listopadu 15 , \\ 70833 Ostrava-Poruba, Czech Republic
}

\begin{abstract}
The present article describes two various methods of determination of thermal conductivity of semi-solid and liquid materials. One is based on experimental measurements of heat flux through a layer of semi-solid material while using the Heat Flow Plates, and the second one uses Peltier Elements to determine the heat flux density. The first method was used to determine thermal conductivity of sludge taken from natural gas coolers. Its value, identified by measurements, was $0.746 \mathrm{~W} \cdot \mathrm{m}^{-1} \cdot \mathrm{K}^{-1}$. The second method was applied to determine thermal conductivity for sludge taken from natural gas filtration units. Values thereof were ranging from $0.608 \mathrm{~W} \cdot \mathrm{m}^{-1} \cdot \mathrm{K}^{-1}$ (at the mean sludge temperature of $22^{\circ} \mathrm{C}$ ) to $0.652 \mathrm{~W} \cdot \mathrm{m}^{-1} \cdot \mathrm{K}^{-1}$ (at the sludge temperature of $43{ }^{\circ} \mathrm{C}$ ).
\end{abstract}

\section{Introduction}

In the execution of the cooling or heating processes it is often required to know the value of thermal conductivity $\lambda$ of semi-solid or liquid materials of unknown composition, particularly in the cases of various heat exchangers, gas coolers, and other equipments the use of which requires identification of the quantity of heat removed/supplied through the heat-transfer surface which is contaminated, or even significantly glazed with such materials. In the analytical heat flow determination, it is necessary to identify several thermal and technical parameters [1-3]. Some of the values of these parameters can be found in physical tables; others must be identified analytically or by experiments. Such parameters include also thermal conductivity of materials. Determination thereof is very complicated, even with substances of known compositions. The present article describes two methods of determination of this coefficient $\lambda$ for the sludge taken from a natural gas cooler and from a natural gas filter at the KS01 Compressor Station in Vel'ké Kapušany.

\footnotetext{
${ }^{*}$ Corresponding author: maria.carnogurska@,tuke.sk
} 


\section{Description of the methodology for measuring the thermal conductivity of sludge}

Standard methods typically applied to identify thermal conductivity were not applicable to the given consistency; therefore, an original laboratory experimental method for measuring the thermal conductivity for arbitrary semi-solid materials was designed. The principle thereof is based on the elementary relation applicable to the heat flux density $q$ at unidirectional steady heat transfer in a planar board (layer) [4-6], i.e.

$$
\lambda=\frac{q \cdot b}{\Delta t} \quad\left(\mathrm{~W} \cdot \mathrm{m}^{-1} \cdot \mathrm{K}^{-1}\right),
$$

where $b$ is the layer thickness (m),

$\Delta t$ - difference in temperatures of both layer surfaces $(\mathrm{K})$.

\subsection{Measurement using the heat flow plates}

Provided that a heat flux density value and the temperature difference may be identified experimentally, then formula (1) can be used for simple identification of the thermal conductivity. Determination of heat flux through a $12.5 \mathrm{~mm}$ thick sludge layer taken from a natural gas cooler was carried out while using an experimental device (Figure 1) consisting of the following parts:

- a block with dimensions of $400 \times 192 \times 85.2 \mathrm{~mm}$ made of electrolytic copper,

- an electric heater providing the necessary heat input for temperatures ranging from 45 to $70{ }^{\circ} \mathrm{C}$,

- an aluminium frame with internal dimensions of $220 \times 140 \times 12.5 \mathrm{~mm}$ in which the measured sludge specimen was placed, hermetically enclosed in the stretch foil,

- the Heat Flow Plates Type FQ 90150-1 heat flow sensor,

- a memory system by AHLBORN, ALMEMO 2390-8 type, recording the heat flow,

- the Grant 2020 measuring centre for continuous temperature scanning.

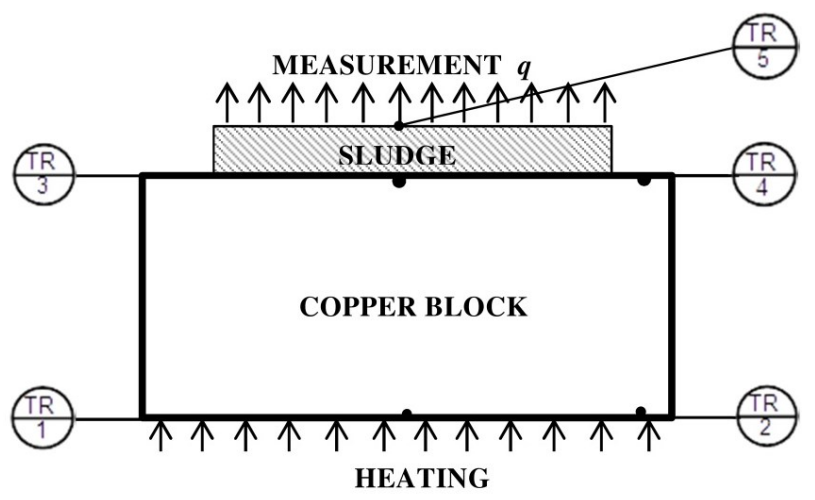

Fig. 1. Scheme of the measuring device.

Prior to the measurement itself, a type of the thermal filed inside the copper block was identified (Figure 2). To achieve stationary temperature distribution in the copper block along its height as well as its width, the block had to be heated from a cold state for the period of approximately 12 hours. An example of temperature curves for $t_{3}$ and $t_{4}$ on the top side of the copper object, after achieving the stationary state, is presented in Figure 3. 
The graph indicates that the temperatures on the top surface under the sludge specimen, as well as next to it, are actually identical. The average difference between them did not exceed $0.07^{\circ} \mathrm{C}$.

After the measurement completion, data files from memories of both centres were exported to a PC, evaluated while using the Excel calculator, and subsequently used to calculate the thermal conductivity.
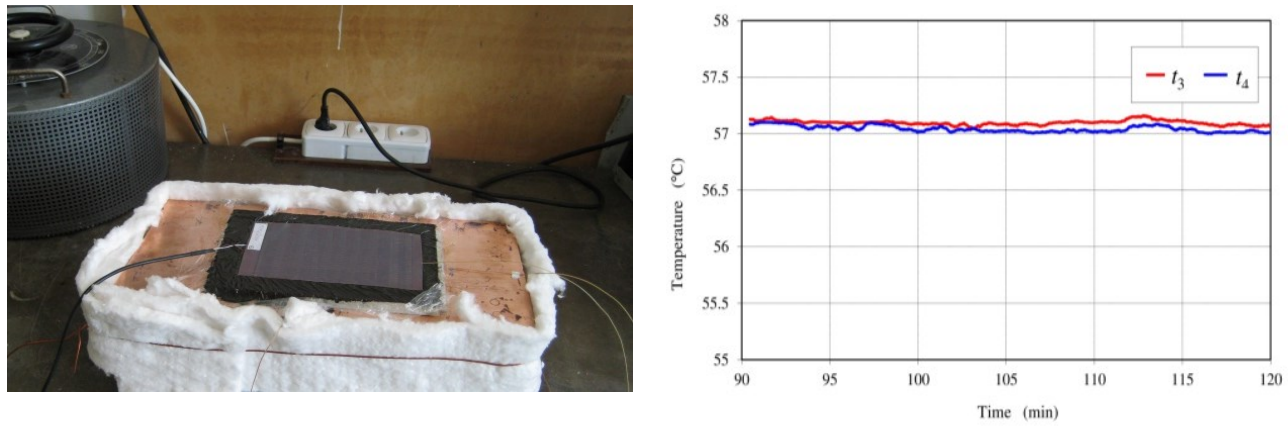

Fig. 2. Experimental device during the Fig. 3. Copper block top surface temperatures. measurement.

In the steady state, the measured values of heat flux $q$ through the sludge layer, within the period of $110 \mathrm{~min}$., were ranging between 201.9 and $232.1 \mathrm{~W} \cdot \mathrm{m}^{-2}$; the average value represented $218.3 \mathrm{~W} \cdot \mathrm{m}^{-2}$. Within the same period of time, the differences in temperatures of the lower and the top sludge surface were ranging between 3.6 and $3.8 \mathrm{~K}$; the average temperature difference was $3.657 \mathrm{~K}$. The measured parameters $q$ and $\Delta t$, as well as the sludge layer thickness of $0.0125 \mathrm{~m}$, were used to determine the thermal conductivity of sludge while using formula (1). It was observed that the average value thereof during the experiment was $\lambda=0.746 \mathrm{~W} \cdot \mathrm{m}^{-1} \cdot \mathrm{K}^{-1}$. The thermal conductivity of the sludge with such average value was used in the thermal calculation of the glazed natural gas cooler.

\subsection{Measurement with the use of Peltier elements}

An alternative to the coefficient $\lambda$ measurement while using the Heat Flow Plates is the measurement carried out while using the device (Figure 4), comprising the Peltier Elements (PE) of the TEC1-12708 type.

In this case again, when identifying the thermal conductivity, it is necessary to respect the Fourier's Law for stationary unidirectional heat conduction. For the purpose of analytical expression of the thermal conductivity, while applying the Fourier's Law, it is necessary to know a particular value of the heat flow passing through the contact surface into the measured material, the thickness of this material layer, as well as the temperatures on both sides of the material layer. It is difficult to determine a particular value of the heat flow passing into the examined material as well as meeting the requirement of conducting the heat only in one direction.

The measured material is put inside a hollow block (1) the bottom of which consists of the PE (4). The vessel is covered with a lid (2) with the attached PE (3). Both elements are directly contacting the material, whereas the PE (3) heats it up from the top side, and the element (4) cools it from the lower side. This prevents the specimen from "stirring" due to free convection. Elimination of the heat gain on the cold side of the PE (3) is provided by the PE (5) located on the top lid surface. The cold side of this element is maintained at 
the same temperature as the cold side of the element (3). This temperature is scanned by electronic temperature sensors (9) and (10). Material specimen temperature is measured by sensor (6) located on the hot side of the PE (3) surface, sensor (7) located in the half-height of the material specimen, and sensor (8) located on the cold side of the PE (4).

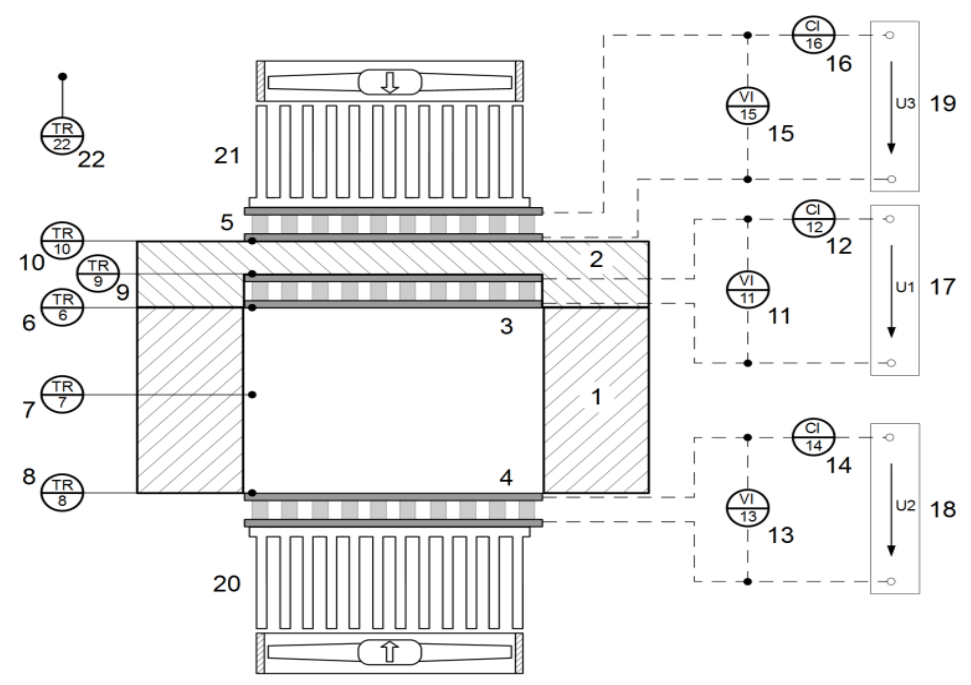

Fig. 4. Device for the measurement of thermal conductivity of materials, based on Peltier Elements. (1 - hollow block, 2 - lid, 3, 4, 5 - Peltier Elements, 6, 7, 8, 9, 10, 22 - temperature sensors, 11, 13, 15 voltmeters, 12, 14, 16 - ammeters, 17, 18, 19 - DC power supplies, 20, 21 - coolers )

Unidirectional heat flow along the height of the measured specimen is achieved by maintaining the specimen temperature difference in the vertical direction, which is ensured by PEs (3), (4), and (5). The average temperature of the examined specimen is maintained at the same value as the ambient temperature, measured by sensor (22), ensuring thus the zero total average heat flow from the external surface of the hollow block (1). An option of changing the mean temperature of the examined specimen is not excluded.

Used temperature sensors are of the SMT 160-30 type. A prototype of the device for the measurement of thermal conductivity of materials of semi-solid consistency is shown in Figure 5. A hollow block is made of foam glass of the FOAMGLAS PERINSUL type which is a good thermal insulator. Its thermal conductivity is $0.04 \mathrm{~W} \cdot \mathrm{m}^{-1} \cdot \mathrm{K}^{-1}$. The volume of the examined material is $32 \mathrm{ml}$. A clear distance between the PEs (3) and (4), i.e. the height of the examined specimen, is $20 \mathrm{~mm}$.

Calibration measurements showed that with regard to accuracy of the used temperature sensors, the optimal difference in temperatures of the top and of the lower sides of the measured specimen is approximately $10^{\circ} \mathrm{C}$. The required temperature difference can be achieved by regulating the PE power supply. 


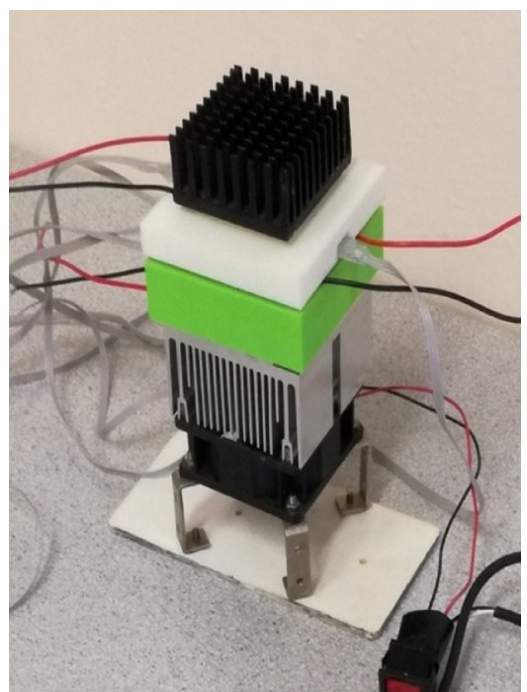

Fig. 5. Device prototype.

$S$ - heat-transfer surface of the PE $\left(\mathrm{m}^{2}\right)$.

Heat is removed from the hot side of the PE (4) by an air cooler (20). The same function for element (5) is served by the air cooler (21). The temperature sensor (7) scans the mean temperature of the specimen and controls the stabilisation of the thermal field of the specimen [7]. PE (4) is supplied by the power supply (18), whereas the voltage is measured by the voltmeter (13) and the current by the ammeter (14). PE (5) is supplied by the power supply (19) the voltage of which is measured by the voltmeter (15) and current by the ammeter (16). Figure 6 shows how the device is connected during the measurement.

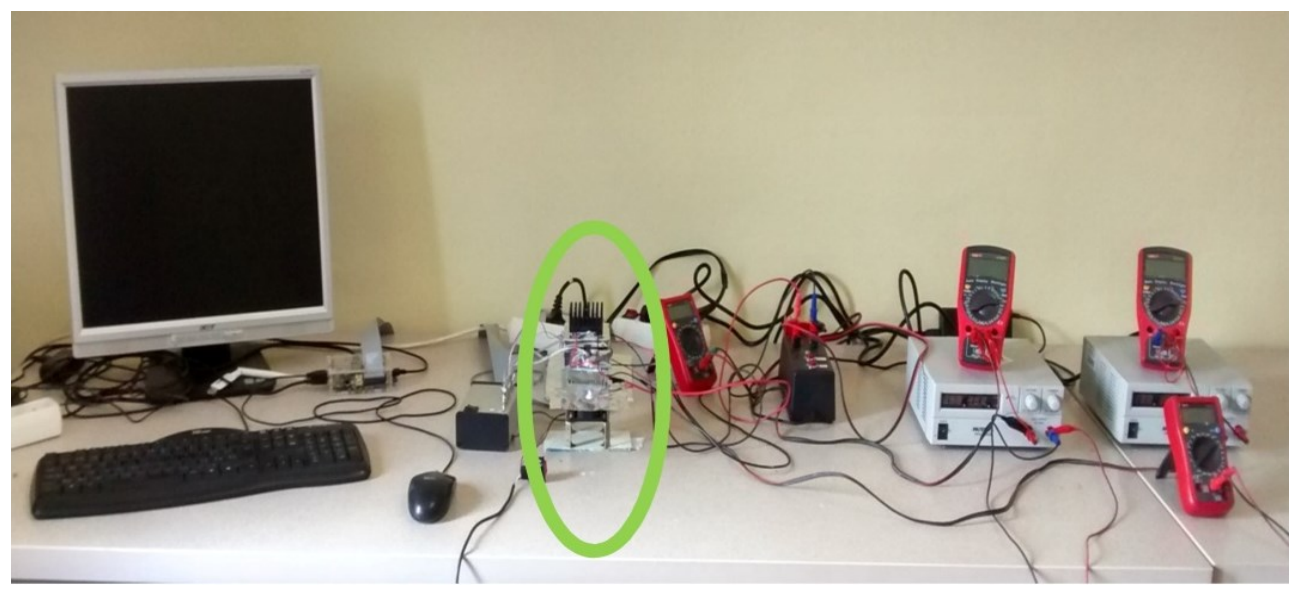

Fig. 6. Device during the measurement.

\section{Conclusion}

The present article describes two different methods of determination of thermal conductivity of semi-solid as well as liquid materials. One is based on the experimental measurement of heat flux through the layer of semi-solid material, while using 
a commercially available planar sensor Heat Flow Plates, and the second one uses the PE. As for practical applications, the second method is more complicated but more accurate. It was not possible to experimentally examine both specimens while applying both methods, as they were not obtained at the same time. The sludge from a natural gas cooler was measured two years before the sludge from a filter was obtained, and at that time the device presented in Figure 4 was not yet constructed.

Results of the measurements of the two types of sludge, while applying different procedures, show the deviation of as much as $19 \%$. This could be explained by different compositions of the two sludge types. Filters are located at the inlet into the compressor station, whereas the coolers are located at the outlet. It is assumable that the sludge taken from coolers is more contaminated with oil that leaks from compressors into the compressed gas.

The value of thermal conductivity of the sludge taken from natural gas coolers was $0.746 \mathrm{~W} \cdot \mathrm{m}^{-1} \cdot \mathrm{K}^{-1}$. The sludge taken from natural gas filtration units was determined for the temperature range from $22{ }^{\circ} \mathrm{C}$ to $43{ }^{\circ} \mathrm{C}$. The $\lambda$ values were ranging from $0.608 \mathrm{~W} \cdot \mathrm{m}^{-1} \cdot \mathrm{K}^{-1}$ to $0.652 \mathrm{~W} \cdot \mathrm{m}^{-1} \cdot \mathrm{K}^{-1}$.

An advantage of measuring the thermal conductivity in a device that uses the PE is the creation of conditions that prevent the formation of free convection in specimens of semisolid or liquid consistency, with concurrent elimination of heat losses into the surrounding environment, in particular by adjusting the mean temperature of the measured specimen to the ambient temperature.

This paper was elaborated within the tasks related to the execution of the KEGA 003 TUKE - 4/2016, APVV-15-0202, ITM S26220220044 and SP2018/94-FMMI VŠB TUO projects.

\section{References}

1. P. Nemec, M. Malcho, Experimental evaluation of cooling efficiency of the high performance cooling device. AIP Conference Proceedings, 1745, article number 020035 (2016)

2. P. Durčanský, Š. Papučík, M. Malcho, Measurement of the performance characteristics of hot air heat exchanger. AIP Conference Proceedings, 1768, article number 020028 (2016)

3. M. Př́hoda, J. Vlček, M. Velička, M. Čarnogurská, R. Pyszko, Heat output of the recuperator for preheating natural gas from a mobile container device. AIP Conference Proceedings, 1768, article number 020016 (2016)

4. M. Rédr, M. Př́íhoda, Základy tepelné techniky. SNTL, Praha (1991), in Czech

5. M. Čarnogurská, M. Př́ihoda, J. Molínek, Determination of deposit thickness in natural gas cooler based on the measurements of gas cooling degree. J. Mech. Sci. Technol. 25, 11, (2011)

6. B. Knížat, F. Urban, M. Mlkvik, F. Ridzoň, R. Olšiak, Numerical simulation of losses along a natural circulation helium loop. AIP Conference Proceedings, 1745, article number 020023 (2016)

7. P. Liptai, B. Dolník, M. Pavlík, K. Zbojovský, M. Špes, Check measurements of magnetic flux density: Equipment design and the determination of the confidence interval for EFA 300 measuring devices. Measurement. 111 (2017) 